\title{
Prostate carcinoma and stem cells
}

\author{
L.M. Antón Aparicio ${ }^{a}$, J. Cassinello Espinosa ${ }^{\mathrm{b}}$, R. García Campelo ${ }^{\mathrm{a}}$, F. Gómez Veiga ${ }^{\mathrm{c}}$, \\ S. Díaz Prado and G. Aparicio Gallego
}

\author{
${ }^{a}$ Medical Oncology Service. CHU Juan Canalejo. Department of Medicine. University of La Coruña. Coruña, Spain \\ ${ }^{b}$ Medical Oncology Service. University Hospital of Guadalajara. Guadalajara, Spain \\ ${ }^{c}$ Urology Service. CHU Juan Canalejo. La Coruña, Spain \\ ${ }^{d}$ Oncology Research Unit. CHU Juan Canalejo. La Coruña, Spain. \\ ${ }^{e}$ Department of Biology. Lisbon University. Lisbon, Portugal
}

\begin{abstract}
Stem cells, as classically defined, are cells with a capacity to self-renew and to generate daughter cells that can differentiate down several cell lineages to form all of the cell types that are found in the mature tissue. Stem cells and tumour cells have many similar features, including infinite lifespan, self-renewal, multidrug resistance, telomerase expression and, in the instance of the prostate, androgen independence. Evidence supports a role for stem cells in the etiology of many types of cancer. The evolution of androgen-independent prostate carcinoma may reflect the emergence of stem like prostate tumour cells. Because cancer may be a disease of stem cell lineages and Shh-Gli signalling controls the behaviour of precursors and of cells with stem cell properties in the mammalian tissues, prostate cancer might derive from inappropriate expansion of prostatic epithelial stem cell lineages caused by abnormal Shh-Gli function. This review attempts to integrate these recent results.
\end{abstract}

\section{Key words}

Stem cells; Prostate cancer; WNT and Hh pathway 


\section{Introduction}

Stem cells generally reside in specialised niches that form a microenvironment which maintains their primitive phenotype. Prostate stem cells may play a critical role in epithelial development and homeostasis. The proximal region and the urethra contain cells that regenerate prostatic tissue far more robustly than cells isolated from the intermediate or distal regions of ducts. These cells survive androgen ablation and regenerate prostatic tissue fully, once androgens are re-administered.

Wnt signalling has been identified as one of the key signalling pathways in cancer, regulating cell growth, motility and differentiation. Because of its widespread activation in diverse human tumour diseases, the Wnt pathway has gained considerable and growing interest in prostate cancer research over recent years.

A series of articles defined the role of Hh signalling in the growth and metastasis of advanced prostate cancer. Molecular mechanisms and pathway components discovered in biochemical, genetic and molecular studies of $\mathrm{Hh}$ signalling during development, particularly in stem cell biology, are now demonstrated to be behind characteristics of tumour cells such as proliferation and invasive behaviour.

\section{Developmental biology}

As a gland, the prostate is composed of many acini that empty into multiple tiny ductules, streaming toward posterior urethral termination in proximity to the seminal colliculus or verumontanum (veru).

Normal development of prostatic ducts requires many coordinated cellular processes, including epithelial proliferation, ductal branching morphogenesis, ductal canalisation, and epithelial and mesenchymal differentiation. In many respects, ductal branching morphogenesis in the prostate resembles that of many other organs (e.g., mammary gland, lung, salivary gland and pancreas).

Development of prostatic ducts begins when solid prostatic buds emerge from the urogenital sinus. These buds grow into the surrounding urogenital sinus mesenchyme.

Today three histologically distinctive glandular zones are defined: peripheral (70-75\%), central (20$25 \%)$ and transition (5-10\%) [1].

The peripheral zone was characterised by ducts radiating laterally from the distal prostatic urethra (veru to apex) and was visualised as an extension coinciding with the ejaculatory duct axis.

The central zone was a proximal wedge-shaped glandular region surrounding the ejaculatory ducts, broad laterally at the base of the prostate, and funnelling to duct orifices at the veru.

A third zone, the transition zone, constituting less than 5\% of the glandular prostate, was found to be com- posed of two separate gland groups bilateral to the urethra, just proximal to the veru.

The human prostate, a tubuloalveolar gland in which ducts and acini have a similar secretory function, is pre- dominantly apocrine because the apical portion of the cell is cast off with some of its secretory products, especially enzymes.

The acinar and ductal secretory epithelial cells pro- duce a great number of measurable substances, including acid phosphatase; lactic dehydrogenase; kallikrein proteases, such as prostate-specific antigen and HK-2; prostaglandin; spermine; fibrinogenase; aminopeptidase; zinc; citrate; cholesterol; tissue plasminogen activator; pepsinogen II; lactoferrin; and others [2, 3]. 


\section{Prostatic epithelial differentiation}

Prostatic development is a complex androgen-dependent process involving a coordinated set of events occurring in both the epithelial and stromal compartments of the gland. Thus, whereas epithelial differentiation is de- pendent on the presence of the urogenital mesenchyme, stromal differentiation is in turn dependent on the presence and differentiation state of the developing prostatic epithelium $[4,5]$.

Ductal canalisation is initiated in the solid epithelial cords from the urethral terminus of the prostatic ducts and proceeds distally toward the ductal tips. As the solid epithelial cords canalise, the epithelium reorganises into two distinct cell populations with luminal and basal cell lineage.

The epithelial component of the prostate gland (Fig. 1) consists of two cell layers, with a luminal secretory- cell layer separated from the basement membrane by a basal layer that exhibits most of the cell proliferation and which is believed to contain the stem cell. Mesenchymal-epithelial interactions in prostatic development

Organogenesis of the prostate is absolutely dependent on mesenchymal-epithelial interaction, as differentiation of both the epithelium and mesenchyme. Development of the prostate is dependent on inductive signals from the mesenchyme [6], and these prostatic inducing signals emanate from spatially discrete areas within the urogenital sinus mesenchyme [7, 8].

The outcome of epithelial-mesenchymal interactions is dependent not only on the source of the inducing mesenchyme, but also on the germ layer origin and responsiveness of the epithelium [9]. Although mesenchyme induces and specifies the differentiation of the epithelium, developmental end points induced by mesenchyme are limited by the developmental repertoire of the germ layer origin of the epithelium.

While mesenchyme induces epithelial differentiation, the epithelium in turn induces smooth muscle differentiation in the mesenchyme. Indeed, both differentiation and morphologic patterning of smooth muscle in the prostate are regulated via cell-cell interactions with epithelium.

Although mesenchymal-epithelial interactions play a fundamental role in development of the prostate, the overall developmental process is elicited by androgens, which regulate prostatic development, growth and function via androgen receptors.

During foetal and prepubertal development, androgens act on the prostatic mesenchyme to induce ductal budding, epithelial proliferation and growth of solid epithelial cords into the mesenchyme. When the ducts canalise, the luminal and basal epithelial cells undergo cytodifferentiation [10, 11]. 

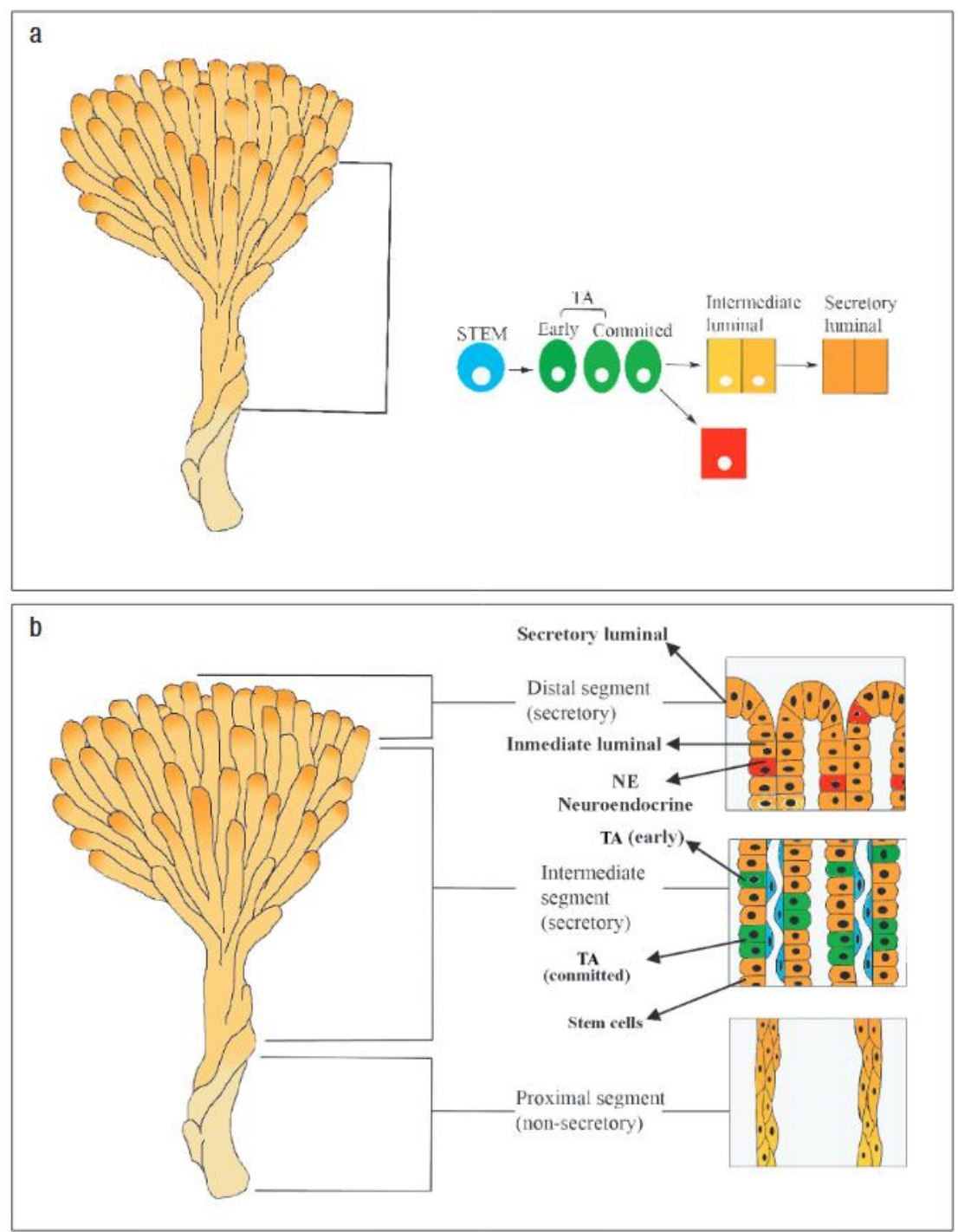

Fig. 1a New cells are formed in the distal segments of the ducts whereas the intermediate section is secretory in function. TA, transit amplifying; NE, neuroendocrine. Adapted from Ref. [99]. b Prostatic ducts arborise throughout the gland and terminate in acini. Adapted from Ref. [100]

\section{Prostate stem cells}

Stem cells are clonogenic cells with self-renewal and differentiation properties, which may represent a major target for genetic damage leading to prostate cancer and benign prostatic hyperplasia. Stem cells remain poorly characterised because of the absence of specific molecular markers that permit us to distinguish them from their progeny, the transit amplifying cells, which have a more restricted proliferative potential (Fig. 2). 


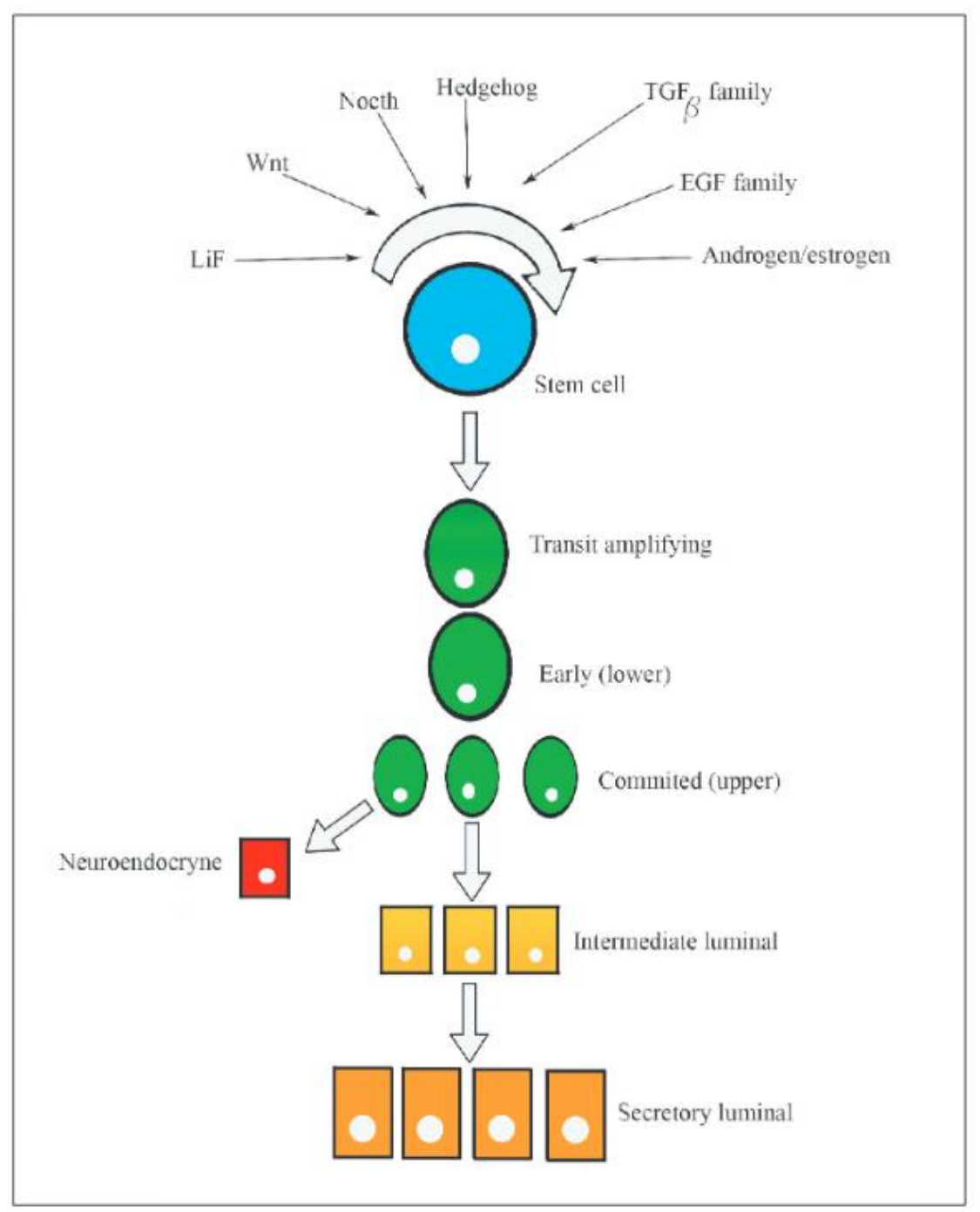

Fig. 2 Prostate stem cell lineage. Adapted from Ref. [101]

Early evidence for stem cells in the prostate came from a set of experiments involving androgen withdraw- al from both human and rat prostate [12-14]. The existence of stem cells in the prostate is probably best illustrated by animal studies investigating the effect of androgen on the prostate. Castration leads to rapid involution of the gland, but once androgen levels are re- stored, the gland completely regenerates. As this cycle of involution-regeneration can be repeated many times, a population of longlived, prostatic epithelial stem cells must exist [15].

It has been reported that two populations of cells capable of regenerating prostatic tissue in an in vivo prostate reconstitution assay are present in different regions of prostatic ducts. The first population (with considerable growth potential) resides in the proximal region of ducts and in the urethra, and the survival of these cells does not require the presence of androgens. The second population (with more limited growth potential) is found in the remaining ductal regions and re- quires androgen for survival [16] (Fig. $3)$. 


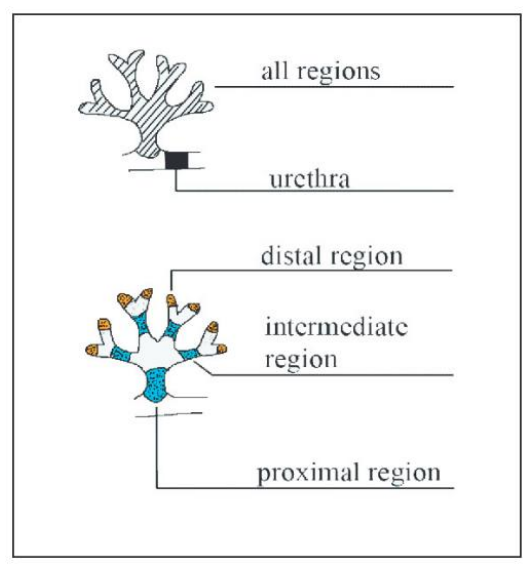

Fig. 3 Location of stem cells
THE FIRST POPULATION RESIDES IN THE PROXIMAL REGION AND THE URETRA

- Cells from the proximal region of ducts as well as urethral cells have considerably greater in vivo regenerative potential than do cells from other ductal regions.

- Some epithelial cells survived and formed small ductal structures in the absence of androgen.

- Primitive cells in the proximal region is unaffected by androgen levels, indicating that cells in this region survive androgen ablation.

- Cells in the proximal region can survive prolonged periods of androgen deprivation and retain full regenerative potential and that urethral cells have similar properties.

THE SECONDS POPULATION (WITH MORE LIMITED GROWTH POTENTIAL) IS FOUND IN THE REMAINING DUCTAL REGIONS

- Survival of these cells requires the presence of androgens.

- Involution of the gland is accompanied by the enrichment of those cells with proliferative potential in the remaining regions of ducts, whereas castration does not affect the proportion of cells capable of forming prostatic tissue in the proximal.

- Castration enriches for cells with a primitive phenotype in the remaining region of ducts, indicating that the more mature cells die during involution.

The proximal region of mouse prostatic ducts is enriched in cells exhibiting stem cell-like properties, namely quiescence, a high proliferative potential, and the ability of single cells to generate progeny of more than one lineage [17]. These cells express Sca-1 [18, 19] and are maintained in a quiescent state by high levels of active transforming growth factor $\beta$ (TGF- $\beta$ ) [20]. The different regions of prostatic ducts are heterogeneous in terms of morphology, telomerase expression and levels of TGF- $\beta$ signalling [15, 20, 21].

\section{Stem cell markers}

Evidence for the stem cell hierarchy in prostate epithelium came from the study of the expression patterns of various markers of differentiation [22-25].

Normal prostate have a basal cell phenotype with expression of CD133, high levels of integrin $\alpha_{2} \beta_{1}$, and keratins $\mathrm{K} 5$ and $\mathrm{K} 14$. These cells give rise to transit-amplifying populations that still have high integrin expression but no longer express CD133.

Basal cells express keratins K5 and K14 together and the anti-apoptotic protein, bcl-2, whereas luminal cells express K8 with K18, CD57, androgen receptor (AR) and the secretory proteins, PSA and prostatic acid phosphatase. Neuroendocrine cells arise from differentiation of normal basal cells and have a complex marker expression pattern of basal and luminal keratins, together with secretion of chromogranin A and serotonin.

CD133 expression was restricted to a small population of cells within the basal layer, but was randomly located throughout acini [26]. High surface expression of integrin $\alpha_{2} \beta_{1}$ has been shown to be associated with stem cells in the prostate. 
In human prostate, stem cells can be distinguished from transit amplifying cells (daughter cells that have a more limited proliferative capacity), by two- to three- fold higher surface levels of integrin $\alpha_{2} \beta_{1}$ [23]: these cells (which make up 3\% of the total basal population) are also randomly located throughout acini [23]. In contrast, others found that stem cells (label-retaining cells) in the rodent prostate are concentrated in the proximal region of the prostatic ducts [27-29]

In conclusion, a subpopulation of $\alpha_{2} \beta_{1}$ basal cells express the CD 133 antigen and this expression correlates with a high proliferative potential and ability to re-generate a fully differentiated prostatic epithelium.

\section{The WNT signalling pathway}

The Wnt pathway directs embryonic growth [30], governing processes such as cell fate specification, proliferation, polarity and migration. It is also implicated in maintenance of stem cell populations.

There are 19 human Wnt genes [31]. Historically, they have been grouped into two classes, canonical and noncanonical. Canonical Wnt family members stabilise $\beta$-catenin, thereby activating transcription of Tcf/LEF- target genes. Noncanonical Wnt family members activate other signalling pathways, such as the planar-cell- polarity pathway, which guides cell movements during gastrulation [32], and the $\mathrm{Wnt} / \mathrm{Ca}^{2+}$ pathway [33]. In some instance, noncanonical Wnt antagonise the canonical pathway [34].

Wnt proteins, a large family of cysteine-rich secreted ligands, bind to a class of seven-pass transmembrane receptors encoded by the frizzled genes [35] transducing a signal to the cytoplasmic protein Dishevelled (Dvl) [36], which is recruited to the membrane, forms a complex with Axin [37] and induces its dephosphorylation [38]. Axin (product of the gene AXIN1) acts as a scaffold protein maintaining the configuration of a complex involving APC (encoded by the Adenomatous Polyposis Coli gene) [39] and $\beta$-catenin (encoded by CTNNB1) [40] and facilitating phosphorylation of both APC [41] and $\beta$-catenin [42] by glycogen synthase kinase $3 \beta$ (GSK3 $\beta$ ) (Fig. 4).

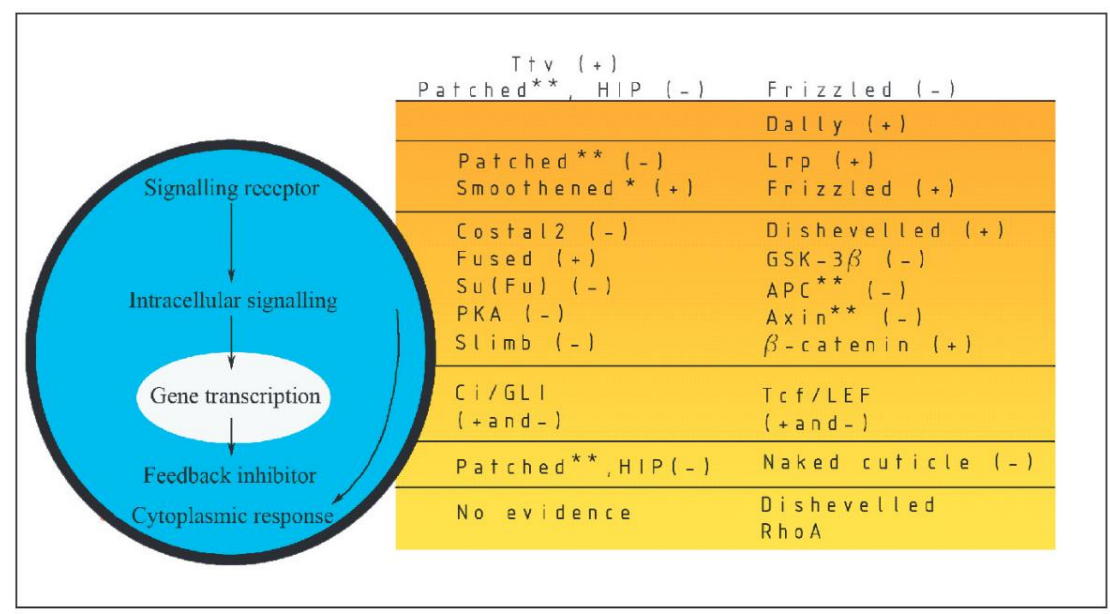

Fig. 4 General characteristics and components of the Hh and Wnt signalling pathways. *oncogene, **tumour suppressor. + and indicate a positive and negative action, respectively. Adapted from Ref. [102] 
The presence of a Wnt ligand at the transmembrane receptor Frizzled (Frz) activates the cytoplasmic protein Dishevelled, which dephosphorylates axin. This de- creases the capacity of Axin to form complexes with APC and $\beta$-catenin. Conductin, a protein with structural homology to axin and encoded by the gene AXIN2 [43], can function in a similar way to axin in this protein complex [44]. Phosphorylation of $\beta$-catenin by GSK3 $\beta$, and hence degradation of $\beta$-catenin by ubiquitin, is decreased. Cytoplasmic $\beta$-catenin thus accumulates and is translocated to the nucleus [45], where it associates with members of the T-cell factor (Tcf) and lymphoid enhancer factor (LEF) family of transcriptional factors [46]. The $\beta$-catenin-Tcf/LEF complex activates transcription of target genes including c-MYC [47], c-jun and fra-1 (components of the AP-1 transcription complex) urokinase-type plasminogen activator receptor (uPAR) [48], and the metalloproteinases matrilysin [49], MMP-26 [50] and cyclin D1 [51].

In summary, activation of the pathway by the presence of a Wnt molecule on the cell surface receptor de- creases phosphorylation of $\beta$-catenin by the APC/ axin/GSK3 $\beta$ complex. $\beta$-Catenin is thus not degraded, and accumulates in the nucleus, where it stimulates transcription of a variety of cancerassociated genes.

\section{The Hh signalling pathway}

The hedgehog pathway plays a critical role in embryonic development [52]. The hedgehog signalling pathway has become widely recognised as one of the major mechanisms for cell-cell communication and tissue polarity.

Various studies have now demonstrated the function of $\mathrm{Hh}$ signalling in the control of cell proliferation, especially for stem cells and stem-like progenitors. Thus, depending on timing and context, Hh growth factors are capable of regulating cell proliferation especially of pre- cursors or stem cells, and cell differentiation.

Secreted Hh molecules bind to the receptor patched, thereby alleviating PTC-mediated suppression of smoothened (Smo), a putative seven-transmembrane protein. Smo signalling triggers a cascade of intracellular events, leading to activation of the pathway through Gli-dependent transcription. The hedgehog receptor Ptch1 is also a target gene of this pathway, which forms a negative feedback mechanism to maintain the pathway activity at an appropriate level in a given cell.

A simplified description of the Hh pathway includes de Hh ligands, their receptor and a few of the molecules that transduce the signal. In mammals there are three distinct Hh ligands with different patterns of expression: Sonic Hedgehog (Shh), Indian Hedgehog (Ihh) and Desert Hedgehog (Dhh). All three Hh ligands bind the transmembrane receptor Patched 1 (Ptch1) (Fig. 3).

In the absence of Hh ligand, Ptch1 inhibits a second transmembrane protein Smoothened (Smo). Hh binding to Ptch1 relieves the repression of Smo and allows Smo to further transduce the Hh signal. This Hh signalling results in the activation of the Gli family of transcription factors: Gli1, Gli2 and Gli3. Gli1 and Ptch1 as well as the gene encoding the Hedgehog interacting protein (Hip) are Hh response genes, and their expression has been used as evidence for active Hh signalling. Expression of Ptch1 or Hip starts a negative feedback loop that shuts down Hh signalling by sequestering Hh ligand. In the cytoplasm the Suppressor of Fused ( $\mathrm{Su}(\mathrm{fu}))$ protein also inhibits transduction of the Hh signal [52]. 


\section{Shh and prostate development}

The role of Shh in regulating induction, proliferation and differentiation of the developing mammalian prostate has been studied most extensively in mouse and rat models: good evidence exists that Shh is required for ductal patterning in the developing prostate.

Development of prostate requires hedgehog signalling. Although the initial formation of prostate buds does not require sonic hedgehog signalling, Shh is critical for maintaining appropriate prostate growth, proliferation and tissue polarity [53-56]. In the adult prostate, however, the activity of the hedgehog pathway is quite low.

Epithelial buds grow and form the prostate ducts. The prostate ducts will elongate and branch extensively both prenatally and postnatally until the final elaborate branching structure of the mature prostate is achieved. Hh function in the prostate seems to centre on the establishment of ductal branching. Shh expression begins in the epithelial layers of the rodent urogenital sinus and concentrates at areas of epithelial budding [57]. Levels of Shh transcripts continue to be elevated as epithelial invaginations become ductal buds. During duct elongation, Shh transcripts localise at the growing distal tips [57-59].

Expression of Shh and activation of the Hh pathway appear to be required for ductal budding and branching [60].

\section{The WNT pathway and prostate cancer}

The Wnt signalling pathway is aberrantly activated in many tumour types, including those of the prostate, in which $\beta$-catenin accumulates in cell nuclei and acts as a transcriptional coregulator for the androgen receptor. Dysfunction of the Wnt pathway in prostate cancer has been assessed in laboratory studies, but there are limited published data pertaining to the incidence of mutations in this pathway.

Upregulation of Wnt-1 was demonstrated in patients with advanced prostate carcinoma [61] and overexpression of the Wnt-5A messenger RNA (mRNA), a member of the Wnt ligand family, was found in one set of prostate tumours [62]. WNT11 expression is elevated in hormone-independent prostate cancer cell lines. Additional analysis indicated that WNT11 expression is also elevated in high-grade prostatic tumours and in hormone-independent xenografts (Table 1).

Table 1 Wnt expression during prostate cancer progression

Prostate cancer cell lines (in vitro cultures)

- WNT 11 expression was found to be low or absent in hormone-dependent cell lines.

- WNT5B, WNT8B and WNT11 were more highly expressed in androgen-independent derivative cell line.

- WNT10B, like WNT11, was more highly expressed in the androgen-independent prostate cancer cell lines.

- WNT7B and WNT14 were more highly expressed in AR-negative prostate cancer cell lines.

- WNT16 expression was more highly expressed in androgen-dependent cell line.

Prostate tissue samples

- WNT11 expression was elevated in all cases that were Gleason grade 7 or above.

- WNT11 was expressed at low levels in nonmalignant cases and in three of three Gleason sum score 6 cases.

Xenograft tumour (CWR22) transplantation

- WNT11 expression increases during the transition from androgen-dependent to androgen-independent prostate cancer in vivo

Results indicate that the expression WNT11 correlates well with hormone-independent growth of prostate cancer cells; increased WNT11 expression accompanies the transition to androgen-independent prostate cancer; WNT11 expression is increased in aggressive or poorly differentiated prostate cancer [79] 
Prostate cancer has been shown to carry mutations in $\beta$-catenin, APC and, interestingly, in $\beta$ TrCP [63-65]. Loss of heterozygosity ( $\mathrm{LOH}$ ) was found in the APC locus in 15\% of prostate tumours [66], or in three of seven tumours [67]. In studies of tumours from Japanese men, APC gene mutation was found in none of 18 tumours and 1 of 36 tumours [68, 69]. LOH [67] and mutation [68] of the APC gene have been detected in some tumour samples, but another group could find no APC mutations [69].

As each of these alterations occurred in about $10 \%$ of cases and were mutually exclusive, activating mutations of the Wnt pathway appear to play a role in at least $30 \%$ of prostate tumours.

The expression of E-cadherin, $\beta$-catenin and GSK3 $\beta$ is diminished in prostate cancer cell lines of greater invasive potential [70]. Expression of $\beta$-catenin in bone metastases appears to be downregulated, compared with that seen in corresponding primary tumours in patients with untreated prostate cancer [71]. Functional interaction of $\beta$-catenin with the androgen receptor was also shown, indicating a cross-talk of both pathways in the development of prostate cancer [64].

Interestingly, the androgen receptor was shown to bind to $\beta$-catenin $[72,73]$ and to transport $\beta$ catenin into the nucleus [74]. Furthermore, transcriptional activity of the androgen receptor was augmented by $\beta$-catenin $[72,73]$, while androgens can block Tcf/ $\beta$-catenin- mediated transcription in prostate cancer cells [75]. This indicates an interplay of Wnt signalling and androgen-dependent pathways, which might be of relevance for prostate cancer development and progression.

In an immunohistochemical study, $\beta$-catenin staining was abnormal in $23 \%$ of 122 radical prostatectomy specimens, compared to $38 \%$ of 90 specimens from transurethral prostatectomies performed in patients with hormone-refractory prostate cancer [76]. This supports the hypothesis that alterations in the Wnt pathway may contribute to progression of prostate cancer to androgen independence. Sublines of apoptosis-resistant LNCaP cells showed increased nuclear $\beta$-catenin expression and increased Tcf/LEF transcription compared to the parent lines [77].

Although, to date, the detection of reproducible genetic lesions in the earliest stages of prostatic intraepithelial neoplasia (PIN) is rare, in transgenic animal models stabilised $\beta$-catenin induced lesions reminiscent of prostatic intraepithelial neoplasia [78]. Expression of a mutant form of $\beta$-catenin produces lesions with histological appearances similar to PIN, the putative precursor of prostate cancer, as early as 10 weeks of age, but these lesions did not progress to invasion or metastasis in animals up to 5 months of age [79].

\section{The Shh pathway and prostate cancer}

The hedgehog pathway plays a critical role in the development of prostate branching. Because data implicating this pathway in cancer are relatively recent, it is too early to know if alternations occur in prostate cancer. To date, there are few reports in the prostate cancer literature.

Activation of the Hh pathway occurs frequently in advanced human prostate cancer: high levels of $\mathrm{Hh}$ target genes, Ptch1 and Hh interacting protein (Hip) are detected in over $70 \%$ of prostate tumours with Gleason scores of 8-10, but in only $22 \%$ of tumours with Gleason scores of 3-6 [80].

Increased protein expression of Ptch1 and Hip indicates activation of the hedgehog pathway. Thus, activation of the hedgehog pathway, as indicated by elevated Ptch1 and Hip expression, is associated with loss of $\mathrm{Su}(\mathrm{fu})$ expression or elevated Hh expression. Target genes of the hedgehog pathway, Ptch1 and Gli1, were all elevated in these tumours, confirming activation of the hedgehog pathway in these tumours. Thus, $\mathrm{Su}(\mathrm{fu})$ inactivation appears to contribute to activation of hedgehog signalling in prostate tumours. In total, 11 of 27 Ptch1- positive prostate cancer specimens have no detectable Su(fu) protein. Prostate cancers with low Gleason scores, however, frequently have detectable $\mathrm{Su}(\mathrm{fu})$ protein, suggesting that loss of $\mathrm{Su}(\mathrm{Fu})$ protein may be associated with prostate cancer progression. 
There are several mechanism by which the hedgehog pathway in these prostate tumours can be activated, including loss of $\mathrm{Su}(\mathrm{fu})$ or overexpression of $\mathrm{Hh}$. In humans the $\mathrm{Su}(\mathrm{fu})$ gene is localised at chromosome 10q24, a region with frequent LOH in several types of cancer, including prostate cancer [77, $81,82]$. Of note, the human $\mathrm{Su}(\mathrm{fu})$ gene product, a repressor of Gli activity, maps to the $10 \mathrm{q} 24$ locus, and thus could be targeted for deletion or codeletion along with PTEN (located at 10q23) in a number of prostate cancers [83].

Also, Shh expression varies from tumour to tumour, which may result from the heterogeneity of prostate cancer. The heterogeneous nature of prostate cancer makes it difficult to screen prostate cancer specimens for $\mathrm{Su}(\mathrm{fu})$ mutations; some prostate tumours had no detectable $\mathrm{Su}(\mathrm{fu})$ protein expression while others contained high levels of Shh protein expression [84].

\section{Clinical significance}

The requirement of Shh for prostate development as well as the misregulation of Shh signalling in a variety of cancers suggests that expression of Shh and/or activation of the Hh pathway might be critical for the develop- ment of prostate cancer. Furthermore, it is interesting to note that multiple components of the Hh pathway are present within chromosomal regions associated with susceptibility to human prostate cancer [84-91].

Prostate cancer also is estimated to have a significant genetic component [92] and familial genetic map- ping studies have identified a series of chromosomal regions that are associated with familial prostate cancer risk. These include regions on chromosomes 1p36, 1q24-25, 8p22, 17p and Xq27-28 that have been identified in individual cohort studies [92-95]. Additional chromosomal regions that may contain prostate cancer susceptibility genes have been recently published and include regions on chromosomes 5q12, 8p21, 15q11, 17q21 and 22q12 [91].

Analysis of data from genetic studies of familial prostate cancer showed that regions implicated in prostate cancer susceptibility contained the genes coding for Hh pathway components, including Gli1, Gli3, Smo and $\mathrm{Su}(\mathrm{fu})$ [96-98].

This is coupled with data that indicate that the hedgehog pathway is present and expressed in human prostate tumours. Analysis of Shh protein immunoreactivity in both normal prostate tissues and tumours demonstrated an upregulation of Shh in prostate tumours, a finding that correlated with the more aggressive tumours, with the Shh-positive tumours having a higher Gleason grade [99, 100]. A metaanalysis of the combined data on Shh and its downstream signalling molecules [99, 100] reveals that while Shh is present in both benign and malignant prostate epithelial cells, the downstream targets Ptch and Gli1 are preferentially activated in metastatic prostate tumours.

Shh signalling in prostate cancer reveals that all the advanced metastatic prostate cancers studied to date have activated the Shh signalling pathway: myriad mechanisms exist that could induce activation of the pathway even in the absence of the ligand. These would include the upregulation or activating mutations in the Hh receptor Ptch or its co-receptor Smo, or the down- stream signalling Gli proteins. There is now a growing knowledge that similar mechanisms are in place regarding the Hh pathway and prostate cancer (Fig. 5). 


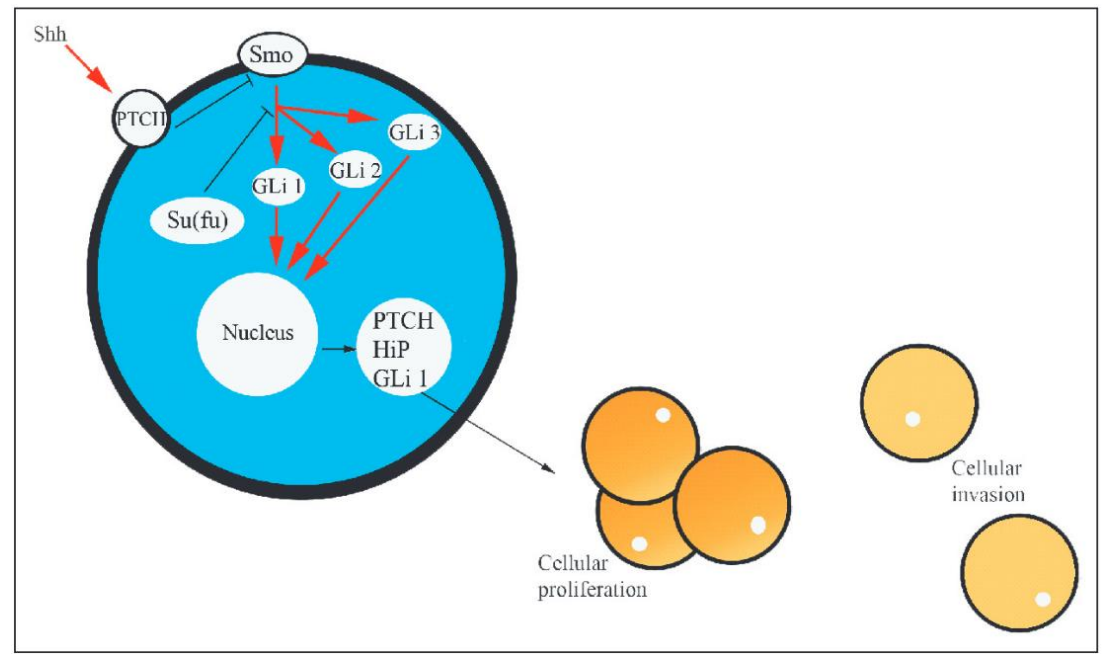

Fig. 5 Prostate cancer changes and the Hh pathway. Shh, PTCH, Hip and Gli 1 are molecules overexpressed. $\rightarrow$, stimulation; - , inhibition. Adapted from Ref. [103]

Analysis of tissue samples has clearly demonstrated the correlation between Shh pathway activation and the presence of prostate cancer. Examination of five different human prostate cancer cell lines (LNCaP, PC3, DU145, TSU and 22RVI) revealed high levels of Gli1 and Ptch1 expression in all lines, indicating activity of the Hh pathway $[99,100]$.

Expression studies in prostate tissue samples and prostate cancer cell lines made a strong case for the importance of Shh signalling in prostate cancer. The key question then became how activity of the pathway affects cellular behaviours associated with tumorigenesis and metastasis.

It has been demonstrated the dependence of prostate cancer cell proliferation on Shh-Gli pathway activity. The data suggest activation of the pathway at different levels in primary prostate tumours and cell lines derived from metastatic lesions. These findings, together with the involvement of this pathway in normal prostate development and growth, indicate that the normal patterning role of Shh-Gli signalling is deregulated in cancer. In contrast, Gli2 and Gli3 do not appear to be consistently expressed in prostate cancer cells.

The establishment of Hh signalling as a major player in the pathogenesis of advanced prostate cancer opens the door to a wide array of basic and translational questions and issues to be resolved. For example, clinical studies might ask whether some measure of Hh signalling activity could provide a more accurate diagnosis of prostate cancer, and identify those for whom there would be an obvious treatment inhibition of the Hh pathway.

\section{Conclusions}

Over the past several years, it has become clear that, similar to what occurs in the haematopoitec system, epithelial tissues are subject to continuous remodelling and renewal in a tightly regulated manner. This tissue renewal involves a hierarchy of cells including slowly proliferating stem cells, rapidly proliferating transit-amplifying cells and various terminally differentiated cells with specialised functions. These putative tissue-specific stem cells have several properties that make them appealing as targets for transforming genetic events. In particular, they are characterised by a capacity for un- limited selfrenewal, and they retain the ability to generate a diverse set of differentiated progeny. 
All adult tissues are made up of lineages of cells consisting of tissue-determined stem cells and their progeny (transit-amplifying cells), which provide cellular lineages producing many cells that differentiate to the mature functioning cells of the tissue. Each tissue has an individual rate of normal tissue renewal.

In any case, all tissues have stem cells, but these stem cells do not all have identical possibilities (potentials) for producing different cell types. Normal stem cells have some properties that are associated with malignant cells. By definition, normal stem cells retain a large capacity for self-renewal and have the ability to migrate to distant parts of the body, where they not only survive but also frequently establish new colonies. These inherent properties of normal stem cells suggest that fewer or different steps may be necessary to produce and transform cancer stem cells as opposed to more differentiated cells. This observation suggests that any cell of a lineage that is not terminally differentiated can still proliferate and can potentially give rise to cancer.

In particular, because the terminally differentiated cells that compose most epithelial tissues rarely proliferate and often are continuously replaced in epithelial linings, the probability that an individual cell will accumulate a set of mutations necessary to create a tumour is small.

The identification of cells with stem-like properties in human tumours raises the question of whether such cells are the target population in which cancer initiation occurs. Although stem cells share some attributes of human tumours, such cells represent only a minuscule fraction of the cells that compose each tissue. Within established tumours, the great majority of the cancer cells cannot sustain the lesion or establish it elsewhere in the body.

Only a few cells within the tumour, the cancer stem cells, are tumorigenic and possess the metastatic phenotype. In general, cancer stem cells resulting from mutations in stem/progenitor cells most likely undergo un- controlled proliferation.

Cancer develops from normal tissues through the accumulation of genetic alterations that act in concert to confer malignant phenotypes. Although some of the genes that, when mutated, initiate tumour formation and drive cancer progression have been identified, the identification of the cell population(s) susceptible to such transforming events remains undefined for the majority of human cancers.

The precise relationship of normal stem cells to cancer stem cells remains undefined, and it remains possible that cancer stem cells only mimic certain stem cell phenotypes or that cancer stem cells reflect an altered early transit-amplifying cell.

The signal that controls which daughter cell of an adult stem cell remains a stem cell and which begins the process of determination may be mediated through a number of signalling pathways including the Oct-4, Wnt/ $\beta$-catenin, Notch, bone morphogenic protein (BMP), Janus family kinase or signalling pathways, etc.

In addition, recent work suggests that many signalling pathways thought to be involved in the maintenance of normal stem cells are found to be mutated in human cancers, including those regulated by Wnt, $\beta$-catenin, PTEN, TGF- $\beta$, Hedgehog and Notch.

The gene encoding Wingless, a founding member of the Wnt family of growth factors, was originally uncovered in the same series of genetic screens that produced mutations in Hh. The mammalian Wnt, on the other hand, was originally identified as an oncogene. Recently, studies have suggested that Wnt signalling activates the proliferation of precursor cells to produce tumours. Wnt pathway dysfunction is an important component of prostatic tumorigenesis.

$\mathrm{Wnt} / \beta$-catenin cell activation pathway is active in maintaining proliferation at an early stage of differentiation and may have a similar role in cancer cells. Wnt signalling affects the orientation of the chromosomes during mitotic division, and abnormalities in the orientation might contribute to mitotic 
disjunctions typical of cancer cells [26]. In general, Wnt/ $\beta$-catenin signalling activates proliferation and inhibits apoptosis, the classic hallmarks of cancer cells.

Hedgehog signalling pathway regulates cell proliferation, tissue polarity and cell differentiation during nor- mal development. The Hedgehog family of growth factors activates a highly conserved signalling system for cell-cell communication. Abnormal activation of the Hedgehog pathway has been demonstrated in advanced prostate cancer and demonstrated that autocrine signalling by tumour cells is required for proliferation, viability and invasive behaviour. The direct link between Hh pathway activity and in vivo prostate tumour growth and metastasis is incredibly exciting. The level of Hedgehog activity correlates with the severity of the tumour and is both necessary and sufficient for metastatic behaviour.

Thus, Hedgehog signalling represents a novel path- way in prostate cancer that offers opportunities for prognostic biomarker development.

Perhaps more promising is the potential to target specific signalling pathways required for stem-cell function. The most likely suspects, on the basis of current thinking, are the Hh and Wnt pathways, both of which have oncogenic potential based on known mutations in pathway components found in several human tumours.

Acknowledgments We thank Prof. P. Cancelo López for careful reading the manuscript and valuable comments, and A. Carro Ramos for typing the manuscript. S. Díaz Prado is supported by an Isidro Parga Pondal research contract by Xunta de Galicia (A Coruña, Galicia, Spain).

\section{References}

1. McNeal JE (1997) Prostate. In: Sternberg SS (ed) Histology for pathologists, 2nd Edn. Lippincott-Raven Publishers, pp 997-1017

2. de Woogt HJ (1991) Biology of the prostate. Prog Clin Biol Res 370:207-212

3. Young CY, Andrews PE, Tindall DJ (1995) Expression and androgenic regulation of human prostate-specific kallikreins. J Androl 16:97-99

4. Sugimura Y, Cunha GR, Donjacour AA (1986) Morphogenesis of ductal networks in the mouse prostate. Biol Reprod 34:961-971

5. Donjacour AA, Cunha GR (1988) The effect of androgen deprivation on branching morphogenesis in the mouse prostate. Dev Biol 128:1-14

6. Cunha GR, Dojacour AA, Cooke PS et al (1987) The endocrinology and developmental biology of the prostate. Endocr Rev 8:338-362

7. Sugimura Y, Norman JT, Cunha GR et al (1985) Regional differences in the inductive activity of the mesenchyme of the embryonic mouse urogenital sinus. Prostate 7:253-260

8. Timms B, Lee C, Aumuller G et al (1995) Instructive induction of prostate growth and differentiation by a defined urogenital sinus mesenchyme. Microsc Res Tech 30:319-332

9. Tsuji M, Shima H, Boutin G et al (1994) Effect of mesenchymal glandular inductors on the growth and cytodifferentiation of neonatal mouse seminal vesicle epithelium. J Androl 15:565-574

10. Hayward SW, Baskin LS, Haughney PC et al (1996) Epithelial development in the rat ventral prostate, anterior prostate and seminal vesicle. Acta Anat (Basel) 155:81-93

11. Hayward SW, Baskin LS, Haughney PC et al (1996) Stromal development in the ventral prostate, anterior prostate and seminal vesicle of the rat. Acta Anat (Basel) 155:94-103

12. English HF, Santen RJ, Isaacs JT (1987) Response of glandular versus basal rat ventral prostatic epithelial cell to androgen withdrawal and replacement. Prostate 11:229

13. Bonkhff H, Remberger K (1996) Differentiation pathways and histogenetic aspects of normal and abnormal prostatic growth: a stem cell model. Prostate 28:98

14. Sugimura Y, Cunha GR, Donjacour AA (1986) Morphological and histological study of castration-induced degeneration and androgen-induced regeneration in the mouse prostate. Biol Reprod 34:973-983

15. Isaacs JT, Schulze H, Coffey DS (1987) Development of androgen resistance in prostatic cancer. Prog Clin Biol Res 243:21-23 
16. Goto K, Salm SH, Coetzee S et al (2006) Proximal prostatic stem cells are programmed to regenerate a proximal-distal ductal axis. Stem Cells 24:1859-1868

17. Tsujimura A, Koikawa Y, Salm S et al (2002) Proximal location of mouse prostate epithelial stem cells: a model of prostatic homeostasis. J Cell Biol 157:1257-1265

18. Burger PE, Xiong X, Coetzee $S$ et al (2005) Sca1 expression identifies stem cells in the proximal region of prostatic ducts with high capacity to reconstitute prostatic tissue. Proc Natl Acad Sci U S A 102:7180-7185

19. Xin L, Lawson DA, Witte ON (2005) The Sca-1 cell surface marker enriches for a prostateregenerating cell subpopulation that can initiate prostate tumorigenesis. Proc Natl Acad Sci USA 102:6942-6947

20. Salm SN, Burger PE, Coetzee $S$ et al (2005) TGF- $\beta$ maintains dormancy of prostatic stem cells in the proximal region of ducts. J Cell Biol 170:81-90

21. Rouleau M, Leger J, Tenniswood M (1990) Ductal heterogeneity of cytokeratins, gene expression, and cell death in the rat ventral prostate. Mol Endocrinol 4:2003-2013

22. Alam TN, O'Hare MJ, Laczko I et al (2004) Differential expression of CD44 during human prostate epithelial cell differentiation. J Histochem Cytochem 52:1083

23. Collins AT, Habib FK, Maitland NJ et al (2001) Identification and isolation of human prostate epithelial stem cells based on alpha (2)beta(1)-integrin expression. J Cell Sci 114:3865

24. Verhagen AP, Aalders TW, Ramaekers FC et al (1988) Differential expression of keratins in the basal and luminal compartments of rat prostatic epithelium during degeneration and regeneration. Prostate 13:25

25. Hudson DL, Guy AT, Fry P et al (2001) Epithelial cell differentiation pathways in the human prostate, identification of intermediate phenotypes by keratin expression. $\mathrm{J}$ Histochem Cytochem 49:271-278

26. Richardson GD, Robson CN, Lang SH et al (2004) CD133, a novel marker for human prostatic epithelial stem cells. J Cell Sci 117:3539-3545

27. Tsujimura A, Koikawa Y, Salm S et al (2002) Proximal location of mouse prostate epithelial stem cells: a model of prostatic homeostasis. J Cell Biol 157:1257

28. Bhatt RI, Brown MD, Hart CA et al (2003) Novel method for the isolation and characterisation of the putative prostatic stem cell. Cytometry 54A:89

29. Hudson DL, O'Hare MJ, Watt FM, Master JRW (2000) Proliferative heterogeneity in the human prostate: evidence for epithelial stem cells. Lab Invest 80:1243

30. Wodarz A, Nusse R (1998) Mechanisms of Wnt signaling in development. Annu Rev Cell Dev Biol 14:59-88

31. Miller JR (2002) The Wnts. Genome Biol 3:REVIEWS3001

32. Heisenberg CP, Tada M, Rauch GJ et al (2000) Silberblick/Wnt1 mediates convergent extension movements during zebrafish gastrulation. Nature (Lond) 405:76-81

33. Kuthl M, Sheldahl LC, Park M et al (2000) The Wnt/Ca2+ pathway: a new vertebrate Wnt signaling pathway takes shape. Trends Genet 16:279-283

34. Torres MA, Yang-Snyder JA, Purcell SM et al (1996) Activities of the Wnt-1 class of secreted signaling factors are antagonized by the Wnt-5A class and by a dominant negative cadherin in early Xenopus development. J Cell Biol 133:1123-1137

35. Yang-Snyder J, Miller JR, Brown JD et al (1996) A frizzled homolog functions in a vertebrate Wnt signaling pathway. Curr Biol 6:1302-1306

36. Noordermeer J, Klingensmith J, Perrimon N, Nusse R (1994) Dishevelled and armadillo act in the wingless signaling pathway in Drosophila. Nature 367:80-83

37. Fagotto F, Jho E, Zeng L et al (1999) Domains of axin involved in protein-protein interactions, Wnt pathway inhibition, and intracellular localization. J Cell Biol 145:741-756

38. Willert K, Shibamoto S, Nusse R (1999) Wnt-induced dephosphorylation of axin releases beta-catenin from the axin complex. Genes Dev 13:1768-1773

39. Bodmer WF, Bailey CJ, Bodmer J et al (1987) Localization of the gene for familial adenomatous polyposis on chromosome 5. Nature 328:614-616

40. Trent JM, Wiltshire R, Su LK et al (1995) The gene for the APC-binding protein betacatenin (CTNNB1) maps to chromosome 3p22, a region frequently altered in human malignancies. Cytogenet Cell Genet 71:343-344

41. Ikeda S, Kishida M, Matsuura Y et al (2000) GSK-3beta-dependent phosphorylation of adenomatous polyposis coli gene product can be modulated by betacatenin and protein phosphatase 2A complexed with Axin. Oncogene 19:537-545

42. Ikeda $\mathrm{S}$ et al (1998) Axin, a negative regulator of the Wnt signaling pathway, forms a complex with GSK-3beta and beta-catenin and promotes GSK-3 beta-dependent phosphorylation of beta-catenin. EMBO J 17:1371-1384 
43. Dong X, Seelan RS, Qian C et al (2001) Genomic structure, chromosome mapping and expression analysis of the human AXIN2 gene. Cytogenet Cell Genet 93:26-28

44. Behrens J, Jenchow BA, Wurtele M et al (1998) Functional interaction of an axin homolog, conductin, with beta-catenin, APC, and GSK3beta. Science 280:596-599

45. Kobayashi M, Honma T, Matsuda $\mathrm{Y}$ et al (2000) Nuclear translocation of beta-catenin in colorectal cancer. Br J Cancer 82:1689-1693

46. Roose J, Clevers H (1999) TCF transcription factors: molecular switches in carcinogenesis. Biochim Biophys Acta 1424:M23-M37

47. He TC et al (1998) Identification of c-MYC as a target of the APC pathway. Science 281: $1509-1512$

48. Mann B, Gelos M, Siedow A et al (1999) Target genes of beta-catenin-T cellfactor/lymphoid-enhancer-factor signaling in human colorectal carcinomas. Proc Natl Acad Sci USA 96:1603-1608

49. Crawford HC, Fingleton BM, Rudolph-Owen LA et al (1999) The metalloproteinase matrilysin is a target of beta-catenin transactivation in intestinal tumors. Oncogene 18:2883-2891

50. Marchenko ND, Marchenko GN, Weinreb RN et al (2004) Beta-catenin regulates the gene of MMP-26, a novel metalloproteinase expressed both in carcinomas and normal epithelial cells. Int J Biochem Cell Biol 36:942-956

51. Tetsu O, McCormick F (1999) Beta-catenin regulates expression of cyclin D1 in colon carcinoma cells. Nature 398:422-426

52. Hooper JE, Scott MP (2005) Communicating with Hedgehogs. Nat Rev Mol Cell Biol 6:306-317

53. Berman DM, Desai N, Wang X et al (2004) Roles for Hedgehog signaling in androgen production and prostate ductal morphogenesis. Dev Biol 267:387-398

54. Podlasek CA, Barnett DH, Clemens JW, Bak PM, Bushman W (1999) Prostate development requires Sonic hedgehog expressed by the urogenital sinus epithelium. Dev Biol 209:28-39

55. Wang BE, Shou J, Ross S et al (2003) Inhibition of epithelial ductal branching in the prostate by sonic hedgehog is indirectly mediated by stromal cells. J Biol Chem 278:1850618513

56. Freestone SH, Marker P, Grace OC et al (2003) Sonic hedgehog regulates prostatic growth and epithelial differentiation. Dev Biol 264:352-362

57. Lamm ML, Catbagan WS, Laciak RJ et al (2002) Sonic Hedgehog activates mesenchymal Gli1 expression during prostate ductal bud formation. Dev Biol 249:349-366

58. Berman DM, Desai N, Wang X et al (2004) Roles for Hedgehog signaling in androgen production and prostate ductal morphogenesis. Dev Biol 267:387-398

59. Pu Y, Huang L, Prins GS (2004) Sonic hedgehog patched Gli signaling in the developing rat prostate gland: lobe-specific suppression by neonatal estrogens reduces ductal growth and branching. Dev Biol 273:257-275

60. Freestone SH, Marker P, Grace OC et al (2003) Sonic hedgehog regulates prostatic growth and epithelial differentiation. Dev Biol 264:352-362

61. Chen G, Shukeir N, Potti A et al (2004) Up-regulation of Wnt-1 and beta-catenin production in patients with advanced metastatic prostate carcinoma: potential pathogenetic and prognostic implications. Cancer 101:1345-1356

62. Iozzo RV, Eichstetter I, Danielson KG (1995) Aberrant expression of the growth factor Wnt-5A in human malignancy. Cancer Res 55:3495-3499

63. Voeller HJ, Truica CI, Gelmann EP (1998) Beta-catenin mutations in human prostate cancer. Cancer Res 58:2520-2523

64. Chesire DR, Ewing CM, Sauvageot J et al (2000) Detection and analysis of beta-catenin mutations in prostate cancer. Prostate 45:323-334

65. Gerstein AV, Almeida TA, Zho G et al (2002) APC/CTNNB1 (beta-catenin) pathway alterations in human prostate cancers. Genes Chromosomes Cancer 34:9-16

66. Brewster SF, Browne S, Brown KW (1994) Somatic allelic loss at the DCC, APC, nm23$\mathrm{H} 1$ and p53 tumor suppressor gene loci in human prostatic carcinoma. J Urol 151:10731077

67. Phillips SM, Morton DG, Lee SJ et al (1994) Loss of heterozygosity of the retinoblastoma and adenomatous polyposis susceptibility gene loci and in chromosomes 10p, 10q and 16q in human prostate cancer. Br J Urol 73:390-395

68. Watanabe N, Kakiuchi H, Kato H et al (1996) APC gene mutations in human prostate cancer. Jpn J Clin Oncol 26:77-81 
69. Suzuki H, Aida S, Akimoto S et al (1994) State of adenomatous polyposis coli gene and rasoncogenes in Japanese prostate cancer. Jpn J Cancer Res 85:847-852

70. Davies G, Jiang WG, Mason MD (2000) Cell-cell adhesion molecules and signaling intermediates and their role in the invasive potential of prostate cancer cells. J Urol 163:985-992

71. Bryden AA, Hoyland JA, Freemont AJ et al (2002) E-cadherin and beta-catenin are downregulated in prostatic bone metastases. Br J Urol Int 89:400-403

72. Truica CI, Byers S, Gelmann EP (2000) Beta-catenin affects androgen receptor transcriptional activity and ligand specificity. Cancer Res 60:4709-4713

73. Yang F, Li X, Sharma M et al (2002) Linking beta-catenin to androgen-signaling pathway. J Biol Chem 277:11336-11344

74. Mulholland DJ, Cheng H, Reid K et al (2002) The androgen receptor can promote betacatenin nuclear translocation independently of adenomatous polyposis coli. J Biol Chem 277:17933-17943

75. Chesire DR, Isaacs WB (2002) Ligand-dependent inhibition of beta-catenin/TCF signaling by androgen receptor T cell factor. Oncogene 21:8453-8469

76. de la Taille A, Rubin MA, Chen NW et al (2003) Beta-catenin-related anomalies in apoptosis-resistant and hormone-refractory prostate cancer cells. Clin Cancer Res 9:18011807

77. Leube B, Drechsler M, Muhlmann K et al (2002) Refined mapping of allele loss at chromosome 10q23-26 in prostate cancer. Prostate 50:135-144

78. Gounari F, Signoretti S, Bronson R et al (2002) Stabilization of beta-catenin induces lesions reminiscent of prostatic intraepithelial neoplasia, but terminal squamous transdifferentiation of other secretory epithelial. Oncogene 21:4099-4107

79. Ahn H, Mazor M, Kawano Y et al (2004) Analysis of Wnt gene expression in prostate cancer: mutual inhibition by Wnt11 and the androgen receptor. Cancer Res 64:7918-7926

80. Sheng T, Li C, Zhang X et al (2004) Activation of the hedgehog pathway in advanced prostate cancer. Mol Cancer 3:29-41

81. Latini JM, Rieger-Christ KM, Wang DS et al (2001) Loss of heterozygosity and microsatellite instability and chromosomal sites IQ and 10Q in morphologically distinct regions of late stage prostate lesions. J Urol 166:1931-1936

82. Kogerman P, Grimm T, Kogerman L et al (1999) Mammalian suppressor-of-fused modulates nuclear cytoplasmic shuttling of Gli-1. Nat Cell Biol 1:312-319

83. Stone DM, Murone M, Luoh S et al (1999) Characterization of the human suppressor of fused, a negative regulator of the zinc-finger transcription factor Gli. J Cell Sci 112: 44374448

84. Gibbs M, Staford JL, McIndoe RA et al (1999) Evidence for a rare prostate cancer susceptibility locus at chromosome 1p36. Am J Hum Genet 64:776-787

85. Kagan J, Stein J, Babaian RJ et al (1995) Homozygous deletions at 8p22 and 8p21 in prostate cancer implicate these regions as the sites for candidate tumor suppressor genes. Oncogene 11:2121-2126

86. Macoska JA, Powell IJ, Sakr W, Lane MA (1992) Loss of the 17p chromosomal region in a metastatic carcinoma of the prostate. J Urol 147: 1142-1146

87. Peters MA, Jarvik GP, Janer M et al (2001) Genetic linkage analysis of prostate cancer families to Xq27-28. Hum Hered 51:107-113

88. Smith JR, Freije D, Carpten JD et al (1996) Major susceptibility locus for prostate cancer on chromosome 1 suggested by a genome-wide search. Science 274:1371-1374

89. Tavtigian SV, Simard J, Teng DH et al (2001) A candidate prostate cancer susceptibility gene at chromosome 17p. Nat Genet 27:172-180

90. Xu J, Meyers D, Freije D et al (1998) Evidence for a prostate cancer susceptibility locus on the X. Chromosome. Nat Genet 20:175-179

91. Xu J, Dinitrov L, Chang BL et al (2005) A combined genomewide linkage scan of 1,233 families for prostate cancer-susceptibility genes conducted by the international consortium for prostate cancer genetics. Am J Hum Genet 77:219-229

92. Lichtenstein P, Holm NV, Verkasalo PK et al (2000) Environmental and heritable factors in the causation of cancer - analyses of cohorts of twins from Sweden. Denmark and Finland. N Engl J Med 343:947-949

93. Badzioch M, Eeles R, Leblanc G et al (2000) Suggestive evidence for a site specific prostate cancer gene on chromosome 1p36. The C.R.C./BPG U.K. Familial Prostate Cancer Study Coordinators and Collaborators. The EU Biomed Collaborators. J Med Genet 37:947-949 
94. Berry R, Shaid DJ, Smith JR et al (2000) Linkage analyses at the chromosome 1 loci1q2425 (HPC1), 1q42.2-43 (PCAP) and 1q36 (CAPB) in families with hereditary prostate cancer. Am J Hum Genet 66:539-546

95. Bova GS, Carter BS, Bussemakers MJ et al (1993) Homozygous deletion and frequent allelic loss of chromosome 8p22 loci in human prostate cancer. Cancer Res 53:3869-3873

96. Sanchez P, Hernandez A, Stecca B et al (2004) Inhibition of prostate cancer proliferation by interference with Hedgehog-GLI1 signaling. Proc Natl Acad Sci U S A 101:112561-12566

97. Easton DF, Schaid DJ, Whittemore AS, Isaacs WJ (2003) Where are the prostate cancer genes? A. Summary of eight genome wide searches. Prostate 57:261-269

98. Xu J, Gillanders EM, Isaacs SD et al (2003) Genome-wide scan for prostate cancer susceptibility genes in the Johns Hopkins hereditary prostate cancer families. Prostate $57: 320-325$

99. Rizzo S, Attard G, Hudson DL (2005) Prostate epithelial stem cells. Cell Prolif 38:363-374

100. Kirby RS. In: An atlas od prostatic diseases. The Parthenon Publishing Group Inc. New York (page 39) 1997

101. Stingl J, Eirew P, Ricketson I et al (2006) Purification and unique properties of mammary epithelial stem cells. Nature 439:993-997

102. Taipale J, Beachy PA (2001) The Hedgehog and Wnt signalling pathways in cancer. Nature 411: 349-354

103. Datta S, Datta MW (2006) Sonic Hedgehog signalling in advanced prostate cancer. Cell Mol Life Sci 63:435-448 